Blickle $\cdot$ Die Revolution von 1525 



\section{Peter Blickle}

\section{Die Revolution von 1525}

4., durchgesehene und bibliografisch erweiterte Auflage

R. Oldenbourg Verlag München 2004 
Bibliografische Information der Deutschen Bibliothek

Die Deutsche Bibliothek verzeichnet diese Publikation in der Deutschen

Nationalbibliografie; detaillierte bibliografische Daten sind im Internet

über http://dnb.ddb.des abrufbar.

(C) 2004 Oldenbourg Wissenschaftsverlag GmbH, München

Rosenheimer Straße 145, D-81671 München

Internet: http://www.oldenbourg-verlag.de

Das Werk einschließlich aller Abbildungen ist urheberrechtlich geschützt. Jede Verwertung außerhalb der Grenzen des Urheberrechtsgesetzes ist ohne Zustimmung des Verlages unzulässig und strafbar. Dies gilt insbesondere für Vervielfältigungen, Übersetzungen, Mikroverfilmungen und die Einspeicherung und Bearbeitung in elektronischen Systemen

\section{Umschlagentwurf: Dieter Vollendorf}

Umschlagabbildung: Thomas Murner, Von dem Großen lutherischen Narren, Straßburg 1522.

Bildvorlage nach der kritischen Ausgabe von Paul Merker, Thomas Murners Deutsche Schriften IX, Straßburg 1918, S. 183.

Gedruckt auf säurefreiem, alterungsbeständigem Papier (chlorfrei gebleicht). Gesamtherstellung: R. Oldenbourg Graphische Betriebe Druckerei GmbH, München

ISBN 3-486-44264-3 